\title{
Noninvasive ventilation in acute neuromuscular respiratory failure due to myasthenic crisis: case report and review of literature
}

\author{
R Agarwal, C Reddy, D Gupta
}

Emerg Med J 2006;23:e6 (http://www.emionline.com/cgi/content/full/23/1/e6). doi: 10.1136/emj.2004.019190

\section{CASE SUMMARY}

A 30 year old male, a follow up case of myasthenia gravis, presented to the Emergency Department with complaints of sore throat, followed by increasing weakness in both the upper limbs and lower limbs. He also gave history of worsening bulbar weakness and progressive dyspnea on exertion. Two years ago the patient had undergone thymectomy. However, following thymectomy, the patient had minimal improvement in symptoms and was continued on glucocorticoids and pyridostigmine. Presently he was on prednisolone $30 \mathrm{mg} /$ day and pyridostigmine $60 \mathrm{mg}$ six times a day. On examination, he was conscious and afebrile with a pulse rate of 96 beats/minute, blood pressure 110/80 mm Hg and respiratory rate of 26/minute. Neurological examination revealed ptosis, dysphonia, bilateral asymmetric extra-ocular muscle weakness, and bifacial weakness. He had a single breath count of 10 and a breath holding time of 12 seconds. Pulse oximetry revealed a saturation of $87 \%$ breathing room air. Arterial blood gases were performed, which confirmed hypercapnic respiratory failure $(\mathrm{pH} 7.3, \mathrm{PaO} 26.9 \mathrm{kPa}, \mathrm{PaCO} 2$ $6.7 \mathrm{kPa}, \mathrm{HCO} 326 \mathrm{mEq} / \mathrm{L})$. The patient was started on supplemental oxygen with nasal cannula at $3 \mathrm{~L} /$ minute. He was shifted to respiratory intensive care unit, where noninvasive ventilation (NIV) was initiated with bi-level positive airway pressure (BiPAP) at inspiratory and expiratory pressures of 15 and $6 \mathrm{~cm} \mathrm{H}_{2} \mathrm{O}$ respectively. He was also started on intravenous immunoglobulin, $2 \mathrm{gm} / \mathrm{kg}$ over 2 days. Pyridostigmine and prednisolone were continued at his usual doses. Serum electrolytes, renal, and liver function tests done were normal. A nasogastric tube was inserted for enteral feeding and intermittent oral suctioning was performed. Patient had subjective and objective improvement with NIV with decrease in respiratory rate and dyspnea. Serial arterial blood gases were done and showed marked improvement (at 4 hours $\left(\mathrm{O}_{2} 10 \mathrm{~L} /\right.$ minute)-pH 7.41, $\mathrm{PaO} 2$ $13.6 \mathrm{kPa}, \mathrm{PaCO} 26.7 \mathrm{kPa}, \mathrm{HCO} 332 \mathrm{mEq} / \mathrm{L}$; Day $\mathrm{l}\left(\mathrm{O}_{2} 6 \mathrm{~L} /\right.$ minute)-pH 7.44, $\mathrm{PaO} 29.1 \mathrm{kPa}, \mathrm{PaCO} 26 \mathrm{kPa}, \mathrm{HCO} 3$ $30 \mathrm{mEq} / \mathrm{L}$ ). Patient improved subsequently and his ventilatory support was discontinued after 3 days. An arterial blood gas analysis done was normal (day 3 (room air)-pH 7.46, $\mathrm{PaO} 29.9 \mathrm{kPa}, \mathrm{PaCO} 24.3 \mathrm{kPa}, \mathrm{HCO} 323 \mathrm{mEq} / \mathrm{L})$. Bulbar weakness also improved and his nasogastric tube was removed. Patient had no complication during the hospital stay and was subsequently discharged on pyridostigmine $60 \mathrm{mg}$ every $4^{\text {th }}$ hourly and prednisolone $40 \mathrm{mg} /$ day.

\section{DISCUSSION}

Noninvasive ventilation (NIV) refers to the provision of ventilatory support to the lungs, without the use of an endotracheal airway. It has emerged as an important tool in the treatment of acute respiratory failure. It can not only reduce the need for invasive mechanical ventilation and its associated complications, but can also reduce the complications associated with stay in the intensive care unit, length of hospital stay and mortality in selected patients. ${ }^{1}$

Long-term use of NIV is recommended for patients with chronic neuromuscular respiratory failure caused by motor neuron disease, Duchenne's muscular dystrophy and other neuromuscular disorders, ${ }^{2}$ and is infact considered the treatment of choice, however, there is no consensus for its use in acute neuromuscular failure. ${ }^{3}$ NIV has been successfully used in patients with acute on chronic respiratory failure and has been shown to decrease the need for invasive ventilation. ${ }^{4}$ The decision to use NIV in acute neuromuscular failure depends upon the severity of the ventilatory failure, the presence or absence of bulbar involvement, and the availability of other effective treatments-for example, in myasthenia gravis and Guillain-Barré syndrome. Patients with severe gas exchange abnormalities, bulbar involvement severe enough to compromise airway management are obvious contraindications; however, there is sparse clinical evidence on the choice of patients who are likely to benefit from NIV.

Myasthenic crisis, defined as an exacerbation of myasthenic weakness causing respiratory failure requiring intubation and mechanical ventilation, occurs in at least $15-20 \%$ of patients with myasthenia gravis. ${ }^{56}$ There is no consensus on how to define myasthenic crisis. ${ }^{6}$ Myasthenic crisis should ideally be defined as exacerbation of myasthenic weakness causing respiratory failure, because not all patients will actually require mechanical ventilation. ${ }^{7}$ Conventionally, treatment has included specific therapy in form of immunotherapy (plasmapheresis or intravenous immunoglobulin), pyridostigmine and pyridostigmine with glucocorticoids and invasive mechanical ventilation. ${ }^{8}$ However, one is likely to see an increasing use of NIV in patient with myasthenic crisis and other acute neuromuscular respiratory failure, especially in situations where other specific supportive therapies are available. In a recent report, bilevel positive airway pressure (BiPAP) prevented intubation in seven of the eleven episodes of myasthenic crisis. Bulbar weakness was documented in seven episodes, including four episodes in which BiPAP prevented intubation. Present of hypercapnia (greater than $50 \mathrm{~mm} \mathrm{Hg}$ ) at onset predicted BiPAP failure. ${ }^{7}$ Infact, a significantly raised $\mathrm{PaCO} 2$ remains an indication for urgent ET intubation as these patients are likely to fail with NIV, whilst having relatively poor airway protection.

In conclusion, BiPAP can be tried first in selected patients with acute respiratory failure especially due to myasthenic crisis and possibly other causes, while awaiting improvement from other specific therapies. However, it should be stressed, that there is a need for closer cardiac monitoring, as patients with myasthenic crisis are prone for cardiac arrhythmias. ${ }^{8}$ Also, repeated clinical assessment and arterial blood gas 
measurements for the first 6-8 hours are generally required to judge the efficacy of NIV and the need for invasive ventilation.

\section{Authors' affiliations}

R Agarwal, C Reddy, S Resident, Department of Pulmonary Medicine, Post-Graduate Institute of Medical Education and Research, Chandigarh-160012, India

Correspondence to: Dr Ritesh Agarwal, Senior Resident, Department of Pulmonary Medicine, Postgraduate Institute of Medical Education and Research, Chandigarh 160012, India; drritesh1@rediffmail.com

Accepted for publication 27 August 2004

\section{REFERENCES}

1 Brochard L, Mancebo J, Elliott MW. Noninvasive ventilation for acute respiratory failure. Eur Respir J 2002;19:712-721.

2 Shneerson JM. Simonds AK. Noninvasive ventilation for chest wall and neuromuscular disorders. Eur Respir J 2002;20:480-487.

3 British thoracic society standards of care committee: Noninvasive ventilation in acute respiratory failure. Thorax 2002;57:192-211.

4 Simonds AK, Muntoni F, Heather S, et al. Impact of nasal ventilation on survival in hypercapnic Duchenne muscular dystrophy. Thorax 1998;53:949-952.

5 Mayer SA. Intensive care of the myasthenic patient. Neurology 1997;48(Suppl 5):S70-75

6 Bedlack RS, Sanders D. On the concept of myasthenic crisis. J Clin Neuromusc Dis 2002:4:40-42.

7 Rabinstein A, Wijdicks EFM. BiPAP in acute respiratory failure due to myasthenic crisis may prevent intubation. Neurology 2002;59:1647-49.

8 Berrouschot J, Baumann I, Kalischewski P, et al. Therapy of myasthenic crisis. Crit Care Med 1997;25:1228-1235. 